\title{
Investigando a organização de processos de trabalho pelo uso de ferramentas analisadoras
}

\author{
Investigating the organization of work processes \\ by the use of analysis tools
}

\section{Ana Paula Rocha de Sales Miranda*}

\begin{abstract}
Resumo - Este artigo analisa os processos de trabalho dos quais o Serviço Social participa em um hospital universitário. Constatou-se, pelo uso das ferramentas analisadoras dos serviços de saúde, a saber, "fluxograma" e "rede de petição e compromissos" (FRANCO; MERHY, 2007) que, em termos gerais, a nova forma de gestão instaurou insegurança, carência de espaços de participação de trabalhadores e usuários e complexificação da classe trabalhadora. Em termos particulares, atestou-se que o trabalho do Serviço Social norteia-se idealmente pela ótica do direito, embora seus efeitos reais sejam limitados por uma lógica interna de organização vertical, centralizada no médico e distante do cuidado em saúde. Além disso, sua autonomia é excessivamente restrita; são inexistentes mecanismos formais estabelecidos que respaldem institucionalmente seu fazer profissional em favor do usuário, e ações planejadas são mínimas. Tal situação exige-lhe romper o imediatismo, redefinir posturas e estabelecer planejamento e trabalho multiprofissional para redução da distância entre seu projeto ideal e as ações reais.
\end{abstract}

Palavras-chave: processos de trabalho; hospital universitário; Serviço Social; ferramentas analisadoras dos serviços de saúde.

\begin{abstract}
This article analyzes the work processes in which Social Work participates at a university hospital. Through the use of analysis tools of health services, "flowchart" and "network of petition and commitments" (FRANCO; MERHY, 2007), it was found that, in general terms, the new way of managing has brought insecurity, lack of opportunities for participation of workers and users, and complexity to the working class. More specifically, it was proven that the practice of Social Work is guided ideally by the logic of the law, although its real effects are limited by an internal logic of vertical organization, centered on the physician and away from healthcare. Furthermore, its autonomy is too restricted, there are no established formal mechanisms to promote institutionally the work for the user, and planned actions are minimal. To solve the situation, it is required to break the immediacy, redefine stances, and establish planning and multidisciplinary work to reduce the distance between its ideal design and actual actions.
\end{abstract}

Keywords: work processes; university hospital; Social Work; analysis tools of health services.

\footnotetext{
*Assistente Social, doutora em Serviço Social pela PUC-SP. Professora Adjunta II do curso de Graduação em Serviço Social da Universidade Federal da Paraíba, pesquisadora do Setor de Estudos e Pesquisas em Saúde e Serviço Social - SEPSASS-UFPB. Correspondência: Cidade Universitária, s/n - Centro de Ciências Humanas, Letras e Artes - Castelo Branco, João Pessoa - PB. CEP: 58051-900. Email: <aprmiranda2@gmail.com>
} 


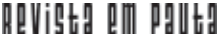

\} INVESTIGANDO A ORGANIZAÇÃO - MIRANDA, A. P. R. S. \}

DOI: $10.12957 /$ rep.2015.21059

\section{Introdução}

Diante da diversidade de cenários vinculados à política de saúde, e das inúmeras questões suscitadas em torno desta área de atuação, este trabalho desenvolveu-se a partir das discussões acerca dos processos de trabalho em saúde, tomando como base a particularidade do trabalho do assistente social dentro de um hospital universitário.

Refletir sobre estes processos de trabalho, dos quais o Serviço Social é partícipe, remete a preocupações cotidianas referentes ao desenvolvimento de práticas que proporcionem o fortalecimento do Sistema Único de Saúde (SUS) e que viabilizem ou facilitem o acesso aos serviços de saúde. Além disso, também a debates que giram em redor dos limites e das possibilidades da prática profissional do assistente social na saúde os quais se retroalimentam nos serviços e nos meios acadêmicos em torno de propostas fundadas no Projeto Ético-Político da Profissão.

A escolha do ambiente hospitalar se deu pela observada especialização e fragmentação das práticas sanitárias e assistenciais que produzem impactos diretos e indiretos sobre a organização e a realização do trabalho em saúde e, portanto, repercutem sobre o trabalho do assistente social, que tem sua autonomia atingida tanto por condições objetivas restritivas, quanto por condições subjetivas voltadas ao cerceamento do direito e a uma cultura verticalizada das relações de trabalho. Ademais, por ser um hospital-escola, além da oferta de serviços e do desenvolvimento de práticas de saúde, há também a configuração de um espaço de formação para os distintos profissionais que atuam na saúde.

A importância de se pensar os processos de trabalho em saúde alude à sua matéria-prima: as necessidades humanas (PEDUZZI; SCHRAIBER, 2008). O recorte no trabalho do assistente social como profissional de saúde se deu por se considerar a importância da sua intervenção nos serviços de saúde, já que lida diretamente com os rebatimentos das relações sociais capitalistas. As expressões da "questão social" são vivenciadas no cotidiano dos sujeitos individuais e coletivos, interferindo sobre sua saúde, o que exige uma atuação crítica que permita o desvendar dos implícitos ou daquilo que a sociedade nega ou vela.

Este artigo tomou como referência a organização dos processos de trabalho empreendidos no Hospital Universitário Lauro Wanderley (HULW), situado em João Pessoa (Paraíba). Para tanto, optou-se pela utilização das ferramentas analisadoras desenvolvidas por Franco e Merhy (2007) junto às assistentes sociais, quais sejam: a organização da "rede de petição e compromissos" e de "fluxogramas".

A opção pelo desenvolvimento destes instrumentos proveio da possibilidade de vislumbrar graficamente os processos de trabalho dos quais o Serviço Social do HULW faz parte, a partir das concepções que as profissionais têm sobre as formas de organização do trabalho. Estes instrumentos 


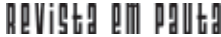

\} INVESTIGANDO A ORGANIZAÇÃO - MIRANDA, A. P. R. S. \}

DOI: 10.12957/rep.2015.21059

configuram-se como ferramentas analisadoras dos serviços de saúde que facilitam o planejamento das ações. Isto porque permitem visualizar as relações estabelecidas entre os diferentes atores na instituição, e destes com atores e instituições externas, além de identificar os problemas que recaem sobre os processos de trabalho desenvolvidos e as necessárias mudanças a serem empreendidas (FRANCO; MERHY, 2007).

\section{Adentrando a lógica de organização do hospital universitário como suporte para compreensão dos processos de trabalho nele desenvolvidos}

Partícipes da rede pública dos serviços de saúde, os hospitais apresentam algumas particularidades em seu modo de funcionamento, uma vez que as atividades neles desempenhadas regem-se sob duas lógicas distintas: a primeira, voltada para a administração e com tendência à burocratização e racionalização de gastos; e a segunda composta pela autoridade profissional, demarcada por características mais democráticas e direcionadas às necessidades assistenciais (AZEVEDO, 2002). Entretanto, devido à autonomia profissional, a citada autora adverte sobre o fato de haver uma independência dos serviços que exige um processo de montagem de estratégias para implantação de modificações.

A referência à burocratização ora empregada associa a burocracia à racionalidade e ao trabalho, ao controle dos processos, ao centralismo, à normatização, ao formalismo, à impessoalidade e à hierarquização - conforme previsto na burocracia moderna de Weber (NOGUEIRA; SANTANA, 2000) -, cuja variação dependerá das condições históricas particulares de cada país.

Sobretudo, ao versar sobre a burocratização, aqui se tomam por base estudos relacionados com a cultura organizacional que apontam traços relativos à representação "em geral" de organizações públicas brasileiras (PIRES; MACEED, 2006). Tal opção partiu do alinhamento com o pensamento de Hofstede (apud PIRES; MACÊDO, 2006), que considera que a dinâmica cultural da sociedade interfere na forma como se apresenta a cultura organizacional.

Entre os principais traços do desenho organizacional público, Pires e Macêdo (2006, p. 82) assinalam: o burocratismo, "[...] o autoritarismo centralizado, o paternalismo, a descontinuidade e a ingerência política". No mesmo sentido, Mattos (2006) adverte que a principal característica do Estado planejador brasileiro - ou desenvolvimentista, ou de modelo regulador - é de ordem política. Para Mattos (2006), a burocracia se forma no país nos anos 1930 - na chamada fase autoritária e burocrática -, sem rompimentos com as relações de poder vigentes e, portanto, mantendo relações patrimonialistas que se interpuseram sobre a formação da burocracia estatal e, segundo Cardoso (apud MATTOS, 2006), sem legitimação 


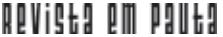

\} INVESTIGANDO A ORGANIZAÇÃO - MIRANDA, A. P. R. S. \}

DOI: $10.12957 /$ rep.2015.21059

ou representatividade em geral da sociedade civil, mas tão somente de segmentos que compunham as classes dirigentes e dos que representavam o capital internacional e financeiro.

Outrossim, Rabello Júnior (s.d.) assinala que esta burocracia em formação se inspirou nas doutrinas de Max Weber, assumindo, como características principais: "formalização, divisão do trabalho, princípio de hierarquia, impessoalidade, competência técnica, separação entre propriedade e administração e profissionalização do funcionário". Ao referirem-se à burocracia como cultura, Nogueira e Santana (2000) asseveram que suas características são mutáveis, mas não abolidas, podendo persistir alguns de seus traços. Embora reforcem a necessidade de sua existência, reconhecem a possibilidade de cristalização dos interesses dos profissionais da burocracia, ao que advertem:

Todo Estado democrático tem de impor limites ao poder da burocracia para que outros objetivos de justiça, especialmente os que se ligam ao bem-estar social, possam ser atendidos, e também possam ser realizados os objetivos da democracia direta, que se cumprem com uma participação dos cidadãos no controle daquilo que o governo faz e como faz. (NOGUEIRA; SANTANA, 2000, n.p.).

A título de esclarecimento, de acordo com Asenjo (apud MORETTO NETO; SILVA; SCHMITT, 2007), ao hospital cabe gerir: a saúde das pessoas; as inter-relações pessoais, baseadas nos vínculos de cuidado entre pessoas doentes e pessoas saudáveis; os interesses de profissionais de saúde, cidadãos, gestores, administradores e proprietários; a objetivação dos interesses desses atores; além da interação entre trabalhadores, assistidos e seus familiares.

A Organização Mundial da Saúde (OMS) compreende os hospitais universitários como Centros de Atenção em Saúde de alta complexidade, assumindo as funções de atendimento médico de nível terciário, participação significativa em atividades de ensino e pesquisa, serviços com alta concentração de recursos físicos, humanos e financeiros e que exercem forte influência e papel político na comunidade onde estão instalados.

Em relação aos hospitais universitários (HUs) brasileiros, o art. 45 da Lei Orgânica da Saúde - Lei no 8.080/90 - incorpora-Os ao SUS, inserindo-os no nível terciário de atenção e preservando sua autonomia (BRASIL, 1990). Entretanto, essa regulamentação não trouxe clareza sobre seu papel, suas atribuições, seu financiamento e sua gestão.

Outrossim, a possibilidade de coadunação de funções relativas aos diferentes níveis de atenção não pode ser ignorada. Esta decorre da tradição desses hospitais de atendimento a demandas espontâneas - muitas vezes relativas ao nível primário - que não foram totalmente solucionadas pelos serviços (redefinidos) da Atenção Básica, à incorporação tecnológica - própria do nível terciário. Soma-se a ela a imprecisão da Lei no 8.080/90 


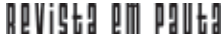

\} INVESTIGANDO A ORGANIZAÇÃO - MIRANDA, A. P. R. S. \}

DOI: $10.12957 /$ rep.2015.21059

e a ineficiente comunicação entre os três níveis de assistência, conformando um sistema ainda fragmentado, apesar de ter sido estabelecida legalmente a construção de rede integrada (MIRANDA, 2010). Desse modo,

A lógica organizacional e a cultura institucional da inserção apenas parcial no Sistema Único de Saúde, forçaram os Hospitais Universitários e de Ensino a adaptarem-se ao atendimento da demanda espontânea, à necessidade de faturamento na tabela do SUS, com as consequentes distorções no atendimento, com prestação de serviços primários e secundários, desperdícios e pouca resolutividade do sistema, levando a um descompasso entre demanda, oferta, modelo assistencial, currículo e pesquisa. (BRASIL, 2003, p. 61).

No Brasil, existem 46 hospitais universitários vinculados ao Ministério da Educação e Cultura (MEC), os quais compõem uma rede de assistência de alta complexidade. Esta exerce papel importante também na realização de pesquisas, no desenvolvimento da ciência e da tecnologia voltadas para a saúde e na formação acadêmica dos cursos da área de saúde vinculados às universidades públicas, tendo sido responsáveis, em 2009, pela realização de 39,7 milhões de procedimentos (HADDAD; SILVA, 2010).

Cabe destacar que as políticas restritivas, fruto da intensificação do ideário neoliberal a partir dos anos 1990, têm conduzido a uma profunda crise dessas instituições, reduzindo sua resolutividade e a qualidade dos serviços oferecidos, aumentando a precarização das condições e dos contratos de trabalho e conferindo rebatimentos negativos tanto para profissionais, quanto para a população usuária (MINISTÉRIO DA EDUCAÇÃO, 2010).

É mister frisar que mesmo com o chamado neodesenvolvimentismo, característico principalmente dos mandatos do Partido dos Trabalhadores (PT), "[...] que visaram a integração da esfera nacional com a internacional com o objetivo de promover o crescimento econômico com inclusão social" (PEREIRA, 2012, p. 734), permaneceu o sucateamento dos hospitais universitários brasileiros, com redução da sua capacidade gerencial e de atendimento assistencial de qualidade.

Em rota oposta à observada insuficiência de recursos destinados aos HUs, houve aumento da demanda oriunda de municípios que não têm condições de oferecer serviços adequados. Esta situação foi agravada pela incorreção da tabela do SUS para pagamento dos procedimentos realizados, em oposição ao custo elevado para manutenção desses hospitais e seus equipamentos, e pela demanda espontânea relacionada a serviços primários e secundários, dificultando, dessa forma, a garantia da equidade e universalidade dos serviços e questionando a integralidade da rede, a despeito da sua importância estratégica.

Buscando reduzir a crise de financiamento dos HUs e a depreciação da sua infraestrutura física e de seus equipamentos, além de tentar responder às solicitações de seus trabalhadores e das entidades sindicais 


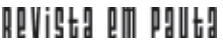

\} INVESTIGANDO A ORGANIZAÇÃO - MIRANDA, A. P. R. S. \}

DOI: 10.12957/rep.2015.21059

que Ihes representam, o Governo Federal instituiu, em janeiro de 2010, o Programa Nacional de Reestruturação dos Hospitais Universitários (Rehuf), por meio do Decreto n. 7.082/2010 (BRASIL, 2010).

Assim, o referido decreto presidencial destinava-se "à reestruturação e revitalização dos hospitais das universidades federais, integrados ao Sistema Único de Saúde (SUS)" (BRASIL, 2010, p. 1). Isto, por meio da criação e implementação de ações que possibilitassem as condições materiais e institucionais necessárias ao desempenho mais adequado desses hospitais, no que tange às dimensões que lhes são pertinentes (ensino, pesquisa e extensão e assistência à saúde).

Com o Rehuf, os HUs seriam financiados por orçamento partilhado entre os Ministérios da Saúde e da Educação, tendo como diretrizes:

I. instituição de mecanismos adequados de financiamento, igualmente compartilhados entre as áreas da educação e da saúde, progressivamente, até 2012;

II. melhoria dos processos de gestão;

III. adequação da estrutura física;

IV. recuperação e modernização do parque tecnológico;

V. reestruturação do quadro de recursos humanos dos hospitais universitários federais; e

VI. aprimoramento das atividades hospitalares vinculadas ao ensino, pesquisa e extensão, bem como à assistência à saúde, com base em avaliação permanente e incorporação de novas tecnologias em saúde. (BRASIL, 2010, p. 2).

Após sua publicação, o decreto seria regulamentado em um prazo de 120 dias. Porém, em "carta manifesto", a Abrahue (2010) declarou-se frustrada a respeito da publicação da Portaria Interministerial n. 883 dos Ministérios da Saúde, Educação, Planejamento, Orçamento e Gestão, de 5 de julho de 2010. Isto porque não houve, nesta portaria, a contemplação do aporte de recursos financeiros de custeio e nem da contratação emergencial de recursos humanos para repor as saídas de funcionários dos quadros efetivos (por morte, exoneração ou aposentadoria), levando, assim, os HUs à grave crise, com possibilidade de fechamento de leitos e comprometimento da assistência, do ensino e da pesquisa nestas instituições.

No tocante ao referido caso dos recursos humanos, a questão remete tanto à existência de contratos precarizados, ligados às fundações de apoio - já condenadas pelo Tribunal de Contas da União (TCU), que estabeleceu como limite para sua solução o ano de 2010 -, quanto à necessidade urgente de contratação para preenchimento de vagas.

A despeito de sua importância e da crise que se arrasta há décadas, e com todas as possíveis e necessárias ressalvas, a "resolução" aparente para os HUs foi a aprovação da Medida Provisória n. 520/2010, que autorizou o Poder Executivo a criar a Empresa Brasileira de Serviços Hospita- 


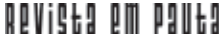

\} INVESTIGANDO A ORGANIZAÇÃO - MIRANDA, A. P. R. S. \}

DOI: $10.12957 /$ rep.2015.21059

lares S. A. (EBSERH) como empresa pública, sob a forma de sociedade anônima, com personalidade jurídica de direito privado e patrimônio próprio, vinculada ao Ministério da Educação (BRASIL, 2010).

A EBSERH representa a adoção de um modelo de gestão baseado em um discurso gerencial e administrativo modernizador, cuja difusão com maior propulsão se deu no país a partir dos anos 1990, o qual foi responsável pela proliferação de Organizações Sociais (OSs), Organizações da Sociedade Civil de Interesse Público (OSCIPs) e fundações estatais neste período. Os principais resultados foram o aumento da terceirização entre os trabalhadores, como consequência da redução de concursos públicos, o sucateamento de instituições públicas e a fragilização do direito em saúde, com evidente "desvio nas prioridades do SUS" e, por conseguinte, das conquistas estabelecidas pelo mesmo, gerando "reiteradas críticas do Ministério Público e do Tribunal de Contas da União" (WEICHERT, 2009, p. 84).

Paradoxalmente, essas últimas consequências vêm sendo empregadas para a propaganda denegritória da saúde pública, "justificando" mudanças verticalizadas e abruptas que pouco ou nada tendem a contribuir para melhoria dos serviços públicos. Conduzem, isto sim, a uma sub-reptícia contrarreforma que, no discurso, se diz "favorável" à reforma empreendida nos anos 1980, como se isto fosse possível. No mesmo sentido das colocações supracitadas, Andreazzi (2013, p. 278) adverte:

[...] Continua a discussão dos novos modelos de gestão, que culminam na proposta atual da EBSERH. Seus defensores atuais partem da inviabilidade do modelo atual de gestão burocrática das instituições públicas, considerado pouco flexível e com poucos incentivos à produtividade dos recursos humanos. Chegam a sofisticar a defesa de fundações e empresas estatais, alegando as práticas políticas arraigadas na cultura organizacional do Estado brasileiro-patrimonialista, autoritário, burocrático e colonizado por interesses privados [...], o que justificaria certa blindagem do SUS, protegendo-o da descontinuidade administrativa e de intercorrências derivadas de manobras da política partidária, agora via Terceiro Setor.

Ainda que o cerne da crise refira-se aos insumos financeiros, também inclui questões relativas ao seu modelo organizativo ainda verticalizado (com baixa governabilidade). Necessita, assim, de descentralização dos serviços e alterações no modelo de gestão (com baixo foco na responsabilização e tênue pactuação com os servidores), bem como no modelo assistencial (centralizado na doença), urgindo mudanças na reorganização dos processos de trabalho (pautados nas polaridades de poder), inclusive para garantia da integralidade das ações.

Desta maneira, a opção pela EBSERH remonta à convivência de uma série de antinomias que, cercadas pelo senso comum da ineficiência do Estado e ratificadas pela oposição público e privado (cujas raízes advêm da montagem da política de saúde brasileira), vêm reproduzindo aquilo 


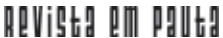

\} INVESTIGANDO A ORGANIZAÇÃO - MIRANDA, A. P. R. S. \}

DOI: 10.12957/rep.2015.21059

que Aciole (2006, p. 34) apontou como "[...] verdadeiros clichês que marcam pares de opostos: eficiência $v s$. ineficiência, agilidade e dinamismo vs. morosidade e burocracia, corrupção vs. integridade moral, eficácia vs. ineficácia", respectivamente relacionados ao privado e ao público. No que concerne ao segundo, tais adjetivos - não virtuosos - explicariam, em parte, o fato de se "aceitar" as inúmeras falhas e desperdícios no serviço público e na gestão pública que Ihes seriam compatíveis, restando-Ihes a transmutação para a lógica que o mercado oferece.

As mudanças em curso, em torno da reorganização da saúde, as transformações no mundo do trabalho e as propostas de um novo modelo de gestão criaram uma atmosfera de insegurança entre os trabalhadores dos hospitais universitários e não deixaram claro o nível das transformações anunciadas e dos impactos que serão produzidos sobre a assistência, tornando ainda mais impreciso o papel dos hospitais universitários e configurando uma espécie de crise de identidade nestes hospitais.

Entre os servidores, há dois posicionamentos diametralmente antagônicos; o primeiro indica que a EBSERH abriria a possibilidade para se romper com a baixa produtividade, a gestão desespecializada, a introdução de novas formas de organização do trabalho, que contemplariam maior comprometimento e requisição de produtividade. Desse modo, corroboraria para melhor atendimento dos usuários e otimização dos processos de trabalho. Tal compreensão se fundaria principalmente na descrença do serviço público, mas também em uma visão positiva da apropriação da lógica de mercado nas empresas públicas que vem sendo propalada desde os anos 1990, bem como na possibilidade de ganhos salariais e de realização de contratação via concursos públicos para celetistas. Isto, em tese, de um lado reduziria o número de trabaIhadores terceirizados e a rotatividade observada, e de outro tornaria possível um maior comprometimento e a adesão permanente dos trabalhadores a novas formas de organização dos processos de trabalho.

Por outro lado, a segunda corrente, que vem sendo encabeçada em grande medida pelos sindicatos e pelas organizações de trabalhadores, acredita que a EBSERH traria insegurança aos trabalhadores. Os motivos para tal seriam a consequente fragilização dos vínculos empregatícios, o aumento do número de terceirizações, a privatização de grande parte dos leitos hospitalares, o crescimento da lógica mercadológica nas instituições públicas e a redução dos espaços decisórios de participação, tanto de trabalhadores, quanto de usuários.

Sobre este último aspecto, particularmente em menção à organização dos processos de trabalho em saúde, Vasconcelos (2009) aponta que a forma de organização dos hospitais se estabelece de modo a engessar as manifestações e contestações dos usuários em prol do acesso aos mesmos e do questionamento à qualidade das ações oferecidas. Assim, resta-lhes percorrer resignadamente os caminhos pré-estabelecidos, por vezes longos, confusos e contraditórios. 


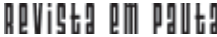

\} INVESTIGANDO A ORGANIZAÇÃO - MIRANDA, A. P. R. S. \}

DOI: $10.12957 /$ rep.2015.21059

A despeito da necessidade que a gerou e dos fatores positivos que possa vir a acarretar - a exemplo dos incontestes fatores negativos -, é mister compreender que a adoção de um modelo de organização e de gestão de serviços como a EBSERH corrobora com a desmesura da sociedade do capital e do mercado, que se coaduna à progressiva heterogeneização e subproletarização do trabalho. Tal modelo de gestão resulta de uma contrarreforma do Estado brasileiro a partir de um viés conservador e regressista, que deita suas raízes na consolidação de um padrão de classes em favor da recomposição da hegemonia burguesa no país, refletindo o baixo compromisso do Estado com a esfera social e com os direitos assegurados em lei, implicando em "profundo retrocesso social" (BEHRING, 2003, p. 22).

Assim, fazendo uma analogia da situação vivenciada no HULW (e em outros hospitais universitários brasileiros) com a "complexificação da classe trabalhadora", identificada por Antunes (2003, p. 50), a partir da adoção da EBSERH passam a conviver profissionais contratados via concurso público, para celetista, e outros regidos pelo Regime Jurídico Único, além dos trabalhadores terceirizados, todos com diferenças salariais e de estabilidade. Gera-se, desta forma, descontentamento entre eles, que podem assumir as mesmas funções em um setor comum e possuir carreiras diferenciadas nas suas diversas particularidades.

No que tange ao atendimento dos usuários, Merhy (2007, p. 28) aponta que a realidade "[...] dos serviços de saúde tem demonstrado que, conforme os modelos de atenção adotados, nem sempre a produção do cuidado em saúde está comprometida efetivamente com a cura e a promoção". O entendimento de "cuidado em saúde" empregado neste trabalho partilha da compreensão de Merhy (2007) e de Pinheiro (2008, p. 113), que o define como "[...] o tratar, o respeitar, o acolher, o atender o ser humano em sofrimento [...], mas com qualidade e resolutividade de seus problemas". Tudo isto a partir de uma interação e abertura entre usuários, profissionais e instituições, na perspectiva de ação integral de forma contínua, no intuito de reduzir o impacto do adoecimento.

A proposta relativa ao "cuidado em saúde" (MERHY, 2007) se baseia na mudança das formas de produção da assistência em saúde. Ou seja, dando maior ênfase na promoção da saúde a partir da vigilância desta e na substituição do modelo médico-hegemônico centrado na realização de procedimentos - mais vinculada à acumulação de capital e ao setor produtivo -, e que dificulta o desenvolvimento de trabalho multiprofissional. Neste sentido, com a mudança, o foco passaria a se localizar nas ações baseadas no desenvolvimento do vínculo entre profissional de saúde e usuário, por meio das quais haja escuta deste e respeito à sua autonomia, responsabilização do profissional no trabalho em ato, integralidade dos serviços e da assistência e ênfase no emprego de tecnologias leves e leve-duras (MERHY, 2007; FRANCO; MAGALHÃES JÚNIOR, 2007). Por sua vez, a baixa realização do "cuidado em saúde" (MERHY, 2007) no ambiente hos- 


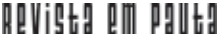

\} INVESTIGANDO A ORGANIZAÇÃO - MIRANDA, A. P. R. S. \}

DOI: $10.12957 /$ rep.2015.21059

pitalar faz com que haja insegurança e sensação de abandono entre a maioria da população que recorre ao atendimento médico-hospitalar (CECILIO, 1997).

Em relação ao Serviço Social no HULW, sua instalação se deu concomitantemente à criação e construção do hospital, cabendo-lhe hoje, em termos formais, "[...] permitir o acesso dos usuários aos serviços institucionais, propiciando condições para o restabelecimento de sua saúde e seu regresso ao contexto familiar e social" (UNIVERSIDADE FEDERAL DA PARAIBA, 2010, p. 116).

Importante destacar que o documento interno do HULW informa, como uma das funções do Serviço Social, empreender a permissão do acesso, o que tacitamente indica que há barreiras institucionais reconhecidas. Isto fere o disposto nos artigos da Lei $\mathrm{n}^{\circ}$ 8.080/90 relativos à universalidade e integralidade do acesso aos serviços de saúde, tendo em vista que a prioridade deveria ser a proteção à vida (BRASIL, 1990).

Assim, o assistente social, além de trabalhar com recursos materiais e, portanto, intervir nas condições objetivas dos usuários que acessam os serviços prestados e/ou organizados por ele, também produz "[...] efeitos na sociedade como um profissional que incide no campo do conhecimento, dos valores, dos comportamentos, da cultura, que, por sua vez, têm efeitos reais interferindo na vida dos sujeitos" (IAMAMOTO, 1999, p. 68). Se isto é certo, ao ter seu trabaIho tangenciado por normas institucionais burocrá-ticas e excludentes, quais os principais efeitos estimados oficialmente para o trabalho deste assistente social?

Buscando-se elucidar estes e outros questionamentos, e entendendo a necessidade de conhecer as particularidades do trabalho do Serviço Social, analisou-se suas ações a partir do Manual Operacional do Serviço Social do HULW (UNIVERSIDADE FEDERAL DA PARAÍBA, 2011). Aqui, considera-se que as principais ações relativas ao trabalho do assistente social estão inseridas, embora não esgotadas, nos "núcleos de objetivação do trabalho do Serviço Social na saúde" definidos por Costa (2006, p. 316), quais sejam: "levantamento de dados", "interpretação de normas e rotinas", "procedimentos de caráter emergencial", e de "natureza socioeducativa", e "atividades de apoio pedagógico e técnico-político". Sobre o trabalho e as ações desenvolvidas pelo Serviço Social, Yasbek (2007, p. 18) assinala:

O Serviço Social como profissão intervém no âmbito das políticas sócio-assistenciais, na esfera pública ou privada, desenvolvendo tanto atividades que envolvem abordagem direta com a população (entrevistas, atendimento de plantão social, visita domiciliar, orientações, encaminhamentos, reuniões, trabalho com indivíduos, famílias, grupos, comunidades, ações de educação e organização popular etc.), como trabalhos de pesquisa, administração, planejamento, supervisão, consultoria e gestão de programas sociais.

Neste sentido, a realização do "levantamento de dados" (COSTA, 2006) ocorre eminentemente por meio da entrevista inicial. Todavia, a 
despeito de representar um acervo de dados rico em determinantes para o processo saúde-doença, está subutilizado, embora seja uma das requisições mais frequentes destinadas ao Serviço Social, cuja intervenção, nos moldes em que vem se realizando, não precisaria estar restrita a esta categoria.

A "interpretação de normas e rotinas" (COSTA, 2006) consiste no repasse de informações relativas ao funcionamento do hospital e de seus serviços ao usuário e familiares. No cotidiano de trabalho, observa-se uma tendência a esperar que a assistente social volte-se menos para o esclarecimento do acesso ao hospital e mais para o enquadramento às normas vigentes, reproduzindo uma lógica de cerceamento de direitos e de controle dos usuários. Tal fato encontra espaço em ambientes onde a autonomia é restrita pela forma rígida e excludente dos processos de trabalho tradicionais.

Quanto aos "procedimentos de natureza socioeducativa" (COSTA, 2006), eles estão majoritariamente voltados ao repasse de informações. Em geral, são realizados no momento das entrevistas, mas também podem acontecer durante os demais momentos em que há o contato com o usuário ou seus familiares. Destinam-se tanto ao esclarecimento de normas e rotinas, à organização de serviços internos e externos ao hospital, quanto à orientação de medidas protetivas, à prevenção em saúde, à realização de exames e aos procedimentos terapêuticos e cirúrgicos, para efetivação de direitos, benefícios, serviços e políticas sociais.

As "ações de caráter emergencial-assistencial" se referenciam principalmente ao atendimento das "[...] urgências sociais que envolvem o processo de prestação de serviços" (COSTA, 2006, p. 332). Enquanto isso, as "atividades de apoio pedagógico e técnico-político" exigem maior planejamento e articulação interprofissional e com os usuários internos e/ou a comunidade, mas não estão significativamente incorporadas ao cotidiano de trabalho do Serviço Social do HULW, excetuando-se os casos das assistentes sociais que participam de alguns dos programas estabelecidos na instituição.

O fato de as ações ou medidas interventivas mais buscadas pelas equipes junto ao Serviço Social se reportarem eminentemente a atividades mais burocráticas - aqui tomadas como racionalizadoras, normatizadoras, hierarquizadoras e controladoras - ou assim tornadas pela instituição, e de haver poucos espaços direcionados a ações de natureza socioeducativa e de apoio técnico-político e pedagógico pelo Serviço Social indicam o engessamento dos processos de trabalho e das ações deste, podendo acarretar tanto a manutenção da hipertrofia do setor médico, quanto um fortalecimento de visões tradicionais da profissão por parte das equipes das quais o Serviço Social faz parte.

Com a implantação da EBSERH, o discurso da assistência baseada nas "linhas de cuidado" passou a ser propalado (FRANCO; MAGALHÃES JÚNIOR, 2007). Segundo estes autores, as "linhas de cuidado" são definidas originalmente como uma imagem que revela a produção do cuidado ao 


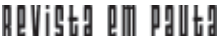

\} INVESTIGANDO A ORGANIZAÇÃO - MIRANDA, A. P. R. S. \}

DOI: $10.12957 /$ rep.2015.21059

expressar o desenho dos fluxos assistenciais na perspectiva de integralidade em saúde. Fazem isto em prol do atendimento das necessidades de saúde do usuário, fornecendo uma referência para a previsão do conjunto mínimo de atividades e procedimentos necessários. Entretanto, embora no HULW tal discurso tenha acenado inicialmente para o desenvolvimento de maior número de ações pedagógicas e técnico-políticas, ele representou mais uma opção formal, pois não tem sido acompanhado pela criação efetiva de espaços para esta intervenção. Ao contrário, observou-se um estreitamento dos espaços de negociação e a sobreposição de informações desconexas. Estas tanto dificultam o acesso ampliado do usuário, quanto imprimem uma rotina incerta aos profissionais, cujas normatizações não são claras. No caso do Serviço Social, ampliam a pseudoimpressão de indefinição do seu fazer profissional (IAMAMOTO, 1999).

Portanto, é preciso compreender que, embora haja a relativa autonomia profissional, o produto do trabalho do assistente social é socialmente determinado. Isto acontece uma vez que os processos de trabalho nos quais se insere encontram-se organizados institucionalmente, conforme os objetivos do empregador, mas aquele também depende dos demais trabalhadores que compõem o trabalho coletivo (IAMAMOTO, 1999). Assim, no caso da saúde, por exemplo, mesmo que execute ações que visam facilitar o acesso do usuário, ainda sofrerá inflexões relativas às concepções de saúde e do direito em saúde que tangenciam as práticas dos demais profissionais com os quais divide ou compartilha o trabalho, que é coletivo (IAMAMOTO, 1999).

Sobre a autonomia profissional, Yasbek (2007) e lamamoto (1999) reconhecem que, apesar de o assistente social ser um profissional liberal, por não dispor do controle das condições materiais e organizacionais necessárias ao seu exercício profissional, ele não exerce a profissão como autônomo, ainda que disponha de relativa autonomia. Desse modo, possui algumas características das profissões liberais, tais como:

[...] a relação singular que pode estabelecer com seus usuários; o caráter não-rotineiro de seu trabalho; a presença de um Código de Ética orientando suas ações; a possibilidade de apresentar propostas de intervenção, a partir de seus conhecimentos teórico-metodológicos e técnico/operativos e, finalmente, a regulamentação legal da profissão. (YASBEK, 2007, p. 20).

De acordo com Merhy (2007, p. 117), o trabalho em saúde, ou o ato de cuidar em saúde, é um "trabalho vivo em ato", um trabalho vivo centrado, ou seja, é um tipo de trabalho que "[...] ocorre no momento mesmo em que se realiza, no imediato fazer a produção do serviço". O destaque à compreensão do trabalho em saúde como "trabalho vivo" fundase na sua dimensão processual - ativa -, na possibilidade de este questionar - e transformar -, no dia a dia, no processo de trabalho, a finalidade do tra- 


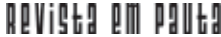

\} INVESTIGANDO A ORGANIZAÇÃO - MIRANDA, A. P. R. S. \}

DOI: $10.12957 /$ rep.2015.21059

balho em saúde, os modelos tecno-assistenciais e os modos de operá-los (PEDUZZI; SCHRAIBER, 2008). Foi a partir desta lógica que se propôs a utilização das "ferramentas analisadoras" de Franco e Merhy (2007) para a investigação da forma como são organizados os processos de trabalho e, mais particularmente, como o Serviço Social está disposto nestes processos, conforme o que se propôs neste artigo.

\section{"Rede de petição e compromissos" e "fluxogramas": ferramentas para a compreensão de processos de trabalho com o objetivo de promover o "cuidado em saúde"}

Segundo Franco e Merhy (2007), as "ferramentas analisadoras" são processos de análise autopedagógicos. Por meio deles, acumula-se e sistematiza-se a prática realizada e o conhecimento da mesma, na medida em que os atores vão se apropriando - criticamente - da realidade da qual fazem parte e sobre a qual intervêm. Portanto, precisam ser feitas pelo coletivo. Neste sentido, a participação da equipe de Serviço Social foi sobremaneira importante para validá-las, já que a identificação da organização dos processos de trabalho partiu de sua percepção acerca dos mesmos. O primeiro passo foi a elaboração da "rede de petição e compromissos" (FRANCO; MERHY, 2007), cujas discussões permitiram identificar as estratégias dos usuários para dirimir as dificuldades de acesso aos serviços oferecidos.

Franco e Merhy (2007, p. 136) definem "rede de petição e compromissos" como "[...] uma descrição das relações intra e interinstitucionais, onde são revelados os estranhamentos e conflitos entre os diversos atores no cenário [...] e revelam os diversos projetos existentes na arena decisória".

Além dessa ferramenta, foi elaborado o "fluxograma" (FRANCO; MERHY, 2007), que desenha a entrada do usuário pelo ambulatório e os percursos que realiza para acessar os demais serviços. Ademais, também o "fluxograma" relativo aos processos de trabalho desenvolvidos nas clínicas do HULW (UTI, cirúrgica, pediátrica, obstétrica, doenças infectocontagiosas e médica). Por meio deste, atestou-se que as ações estão voltadas a assegurar o desenvolvimento do tratamento dos usuários, articulando-se, sempre que necessário, com as famílias.

O "fluxograma descritor" é "[...] uma representação gráfica do processo de trabalho, elaborado de forma usuário-centrado, com riqueza de detalhes para perceber os aspectos da micropolítica da organização do trabalho e da produção de serviços" (FRANCO; MERHY, 2007, p. 135136). Por "usuário-centrado" entende-se o modelo de serviço em que o usuário é o fator determinante para a estruturação e organização do serviço e do processo de produção da saúde (FRANCO; MAGALHÃ̃S JÚNIOR, 2007).

A abordagem para a montagem das citadas ferramentas foi iniciada pela pesquisadora responsável pelo trabalho ora apresentado. No momento 


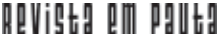

\} INVESTIGANDO A ORGANIZAÇÃO - MIRANDA, A. P. R. S. \}

DOI: 10.12957/rep.2015.21059

de sua elaboração, coube a ela a orientação e o monitoramento, bem como a posterior montagem gráfica das ferramentas, o seu detalhamento e a sua análise (MIRANDA, 2011).

Franco e Merhy (2007) apontam que, em geral, nas análises dos serviços de saúde, há uma tendência ao direcionamento para as questões macroestruturais. Eles chamam a atenção para a necessidade de que essas análises se voltem para as questões da micropolítica da organização dos serviços e das relações intra e interinstitucionais, de modo que, a partir daí, possam ser estabelecidas estratégias para as mudanças necessárias. Para tanto, no início da montagem das ferramentas, são lançadas questões que devem ser examinadas de maneira a explicar a importância e validade do processo. Neste sentido, ao se questionar o porquê da avaliação do serviço, a resposta gerada propôs auxiliar na conquista de espaços do Serviço Social dentro do hospital e garantir a ampliação de sua autonomia perante as demais categorias.

Um segundo ponto, relacionado a quem servirá esta avaliação, a priori teve sua positividade atrelada às próprias assistentes sociais, que buscam participar mais dos processos microdecisórios da instituição e, assim, promover mudanças nos processos de trabalho dos quais o Serviço Social é partícipe. Porém, não só às assistentes sociais, mas também aos usuários que teriam acesso facilitado e/ou de maior qualidade, se esses processos estivessem mais voltados às suas necessidades.

Entretanto, caberia ainda uma outra questão: de que forma viabilizar as mudanças possivelmente identificadas como necessárias? Neste caso, há que se pensar em mudanças como processos, tangenciadas por negociações continuadas - e por vezes conflituosas - entre os diversos atores, tomando como base o compromisso com a saúde pública e com o usuário. Neste sentido, o uso das "ferramentas analisadoras" (FRANCO; MERHY, 2007) para a compreensão dos processos de trabalho permitiria o estabelecimento de estratégias montadas pelo planejamento conjunto, norteado pela resolução dos principais problemas e entraves identificados.

Conforme se pôde perceber, a partir da "rede de petição e compromissos" (FRANCO; MERHY, 2007) do Serviço Social do HULW, a categoria se encontra determinada pela resolutividade do serviço médico e pela organização interna do hospital. Assim, conforme a disposição estabelecida no hospital - fato ainda demasiadamente presente nos serviços de saúde - o Serviço Social, a exemplo de outras profissões, permanece intervindo de forma complementar à ação do médico (BEZERRA; ARAÚJO, 2005).

Em relação ao usuário, constatou-se que, ao chegar ao hospital, ele encontra uma organização montada não para facilitar seu acesso, mas para ratificar uma rotina a ser seguida de modo a garantir a lógica pré-estabelecida (PIRES; MACÊDO, 2006), sem transtornos. Cabe, então, ao Serviço Social a facilitação desse acesso, embora não disponha de protocolos que respaldem essa prática ou que Ihe atribua poder de atuação conjunta com 


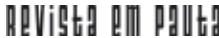

\} INVESTIGANDO A ORGANIZAÇÃO - MIRANDA, A. P. R. S. \}

DOI: 10.12957/rep.2015.21059

as demais categorias profissionais, o que the impõe a necessidade de "negociações" permanentes e desiguais no que tange às relações de poder.

Restou demonstrar que este usuário chega ao hospital por quatro caminhos possíveis: via marcação pela Estratégia de Saúde da Família atualmente responsável pela intermediação do usuário aos serviços de saúde locais -; referenciado para atendimento no Programa de Atenção Multidisciplinar ao Adolescente (Proama) ou no Serviço de Atenção Especializada Materno-Infantil/Hospital Dia (SAE-MI), que atendem respectivamente crianças e adolescentes e crianças e gestantes portadoras do HIV, podendo tanto ser encaminhados por outros serviços quanto procurar o hospital de maneira espontânea, dado ser referência nestes dois tipos de atendimentos; por demanda espontânea; e ainda por transferência de outros serviços, após encaminhamento por verificação de vagas no Sistema de Regulação (Sisreg), as quais devem ser confirmadas e negociadas previamente.

Através da "rede de petição e compromissos" (FRANCO; MERHY, 2007), percebeu-se que a assistente social é requisitada tanto pelo usuário quanto pelo médico, mas a figura central determinante é a do médico, que irá solicitar o que deve e o que pode ser feito. Já ao usuário caberá basicamente a resignação de aceitar o que for possível ser feito, o que gera sentimento de frustração e uma visão limitada da capacidade de intervenção profissional. Entende-se que isto somente poderia ser minimizado se houvesse o estabelecimento efetivo de planejamento permanente de atividades das equipes e de engendramento de trabalho multiprofissional.

Peduzzi (2008, p. 423) conceitua o trabalho multiprofissional como um trabalho coletivo, pautado na relação recíproca entre os diversos profissionais em torno das intervenções técnicas, "configurando, através da comunicação, a articulação das ações e a cooperação".

Não seria exagero ponderar que a limitação dos espaços decisórios do Serviço Social causa não apenas, aos usuários, a sensação de baixa qualidade dos serviços prestados (GASTER apud MENDES, 2002), mas também frustração entre os profissionais que, em determinados casos, cedem ou são forçados diuturnamente a ceder à lógica mantenedora do status quo, assemelhada a algo intransponível, cuja "adesão" - acrítica ou não se dá em maior ou menor grau, seja via concessão temporária, seja pela aceitação ou ainda pela resignação.

Contudo, há que se lembrar que "[...] o produto obtido não depende exclusivamente da vontade e do desempenho individual do profissional" (IAMAMOTO, 1999, p. 111), cujas funções e especializações requeridas são organizadas dentro de condições sociais dadas pela instituição empregadora, que é quem dispõe dos meios de trabalho necessários à sua efetivação.

No caso dos usuários, para enfrentamento desta situação de marginalização dos seus interesses, a análise apontou que estabelecem-se diversas estratégias - legais ou não - para que consigam acessar os serviços oferecidos. É mister destacar que essas estratégias são eminentemente re- 


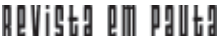

\} INVESTIGANDO A ORGANIZAÇÃO - MIRANDA, A. P. R. S. \}

DOI: 10.12957/rep.2015.21059

gistradas ou "solucionadas" pelo Serviço Social e, por vezes, ignoradas e/ ou desconhecidas por outras categorias, já que não lhes compete solucionálas ou ouvi-las.

Note-se que o usuário somente será ouvido no momento da entrada, pelo atendimento agendado, ou quando recorre ao Serviço Social, na demanda espontânea. Nos demais momentos, outros profissionais representam sua necessidade, sem que ele tenha espaços para se vocalizar, tornando a lógica do hospital inacessível à sua compreensão, ainda mais complexificada pela situação de constrangimento, sofrimento e abandono a que está sujeito. De acordo com Pires (2008, p. 164), "nos hospitais públicos e na grande maioria dos hospitais privados do país, o entrar na instituição significa perder a identidade e aceitar as regras impostas".

Assim, como o usuário ocupa uma posição marginal no hospital, posto que os serviços ainda não são "usuário-centrados" (FRANCO; MAGALHÃES JÚNIOR, 2007), concluiu-se que o Serviço Social tem seus pedidos feitos pela instituição - nas figuras dos diretores, do superintendente e da equipe médica - para o seu favorecimento. A expectativa de quem faz estes pedidos é de que o Serviço Social contribua para o bom andamento e funcionamento do nosocômio, a partir da manutenção da organização centrada na burocracia interna, decorrente de uma cultura normativo-burocrática, arbitrária e vertical.

Outrossim, constatou-se que a micropolítica da organização, em termos gerais, encontra-se tangenciada por relações de baixa interação entre as equipes, em que cada categoria e profissional tem os seus saberes e trabalha a partir destes, acionando-os para realização de ações que lhe são particulares, o que dificulta o trabalho multiprofissional.

Partindo da análise empreendida por Franco e Merhy (2007), percebe-se a existência de vários e distintos hospitais, conforme o sujeito a experienciá-los. O primeiro hospital remete ao burocrático, determinante, por vezes sufocante e quase intransponível, dando a sensação de eternidade à forma de organização, somada às falhas e omissões observadas.

O segundo hospital reporta-se aos preceptores, aos médicos docentes que o veem como o espaço para o aprendizado, a testagem, onde Ihes interessa mais o que foge aos "casos usuais", como espaço de referência para a consecução e repasse do saber.

Um terceiro hospital é experienciado por outro grupo de profissionais da saúde, que o veem como o local de trabalho. Não de qualquer trabalho, mas do trabalho estável, protegido, do servidor público, lugar de baixo compromisso e responsabilidade, paternalismo e apego ao poder (PIRES; MACÊDO, 2006) - em parte compatível com as condições de trabaIho precárias, mas consonante com a atmosfera em vigor do desmando protegido. O comum entre ambos é o lugar secundário que destinam ao usuário.

O quarto hospital reporta-se ao lugar que o Serviço Social procura garantir (COSTA, 2006), o lugar do acesso, ignorado e necessário, onde 


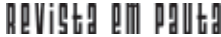

\} INVESTIGANDO A ORGANIZAÇÃO - MIRANDA, A. P. R. S. \}

DOI: $10.12957 /$ rep.2015.21059

compromisso com o direito e improviso para o trabalho caminham juntos. Paradoxalmente, ao mesmo tempo, um completa e nega o outro.

De sua parte, o quinto hospital destoa dos demais, posto ser o lugar da garantia da saúde pela oferta de serviços de alta complexidade. Encara sua missão de prestar assistência médica e de desenvolver atividades de ensino, pesquisa e extensão, fazendo disso uma meta, cujas ações são empreendidas por profissionais capacitados e responsáveis com o bemestar e a recuperação do paciente.

Há que se falar ainda em um sexto hospital, o que representa a linha final, a última chance de ter seu direito assegurado, ainda que, perdoado o trocadilho, tão inseguramente assegurado ao cidadão sujeitado ao "favor" e à "concessão", por ser uma demanda espontânea e não prevista/agendada no sistema de referenciamento da saúde.

Objetivando detalhar melhor a organização dos processos de trabalho, dos quais faz parte o Serviço Social, e as relações inerentes à micropolítica neles contidas, foram construídos, entre a equipe do Serviço Social do HULW, os "fluxogramas" daqueles processos (FRANCO; MERHY, 2007; MIRANDA, 2011). Também pelo "fluxograma" detectou-se que, nos casos em que o usuário não está com atendimento agendado, a rotina garantida pela normatização e burocratização internas ao hospital implicará em uma verdadeira peregrinação para o usuário na busca pelo acesso aos serviços. Deste modo, cabe à assistente social agilizar os encaminhamentos necessários ao atendimento do usuário, bem como orientá-lo quanto à forma que deverá portar-se para conseguir a marcação dos procedimentos oferecidos no hospital. Tal burocratização é assim explicada por Pires (2008, p. 163):

Essas instituições se organizam sob regras rígidas, que auxiliam no distanciamento dos trabalhadores das características humanas do seu objeto de trabalho, ao mesmo tempo em que propiciam a defesa dos interesses corporativos, em oposição à reflexão sobre a globalidade do processo assistencial.

Pela elaboração do "fluxograma" (FRANCO; MERHY, 2007), notou-se que, embora a assistente social interfira para garantir o atendimento do usuário, isto não se faz pela ótica do direito assegurado, mas a partir de relações estabelecidas internamente. A elas se recorre para supressão da demanda e dos conflitos, ainda que a referida intervenção suscite inúmeros embates entre o Serviço Social e as demais categorias, notadamente os médicos e enfermeiros. Configura, assim, entre as equipes de saúde uma imagem do assistente social como o "profissional do jeitinho", o que corrobora com o "mito da indefinição profissional" (IAMAMOTO, 1999, p. 110).

A determinância das posturas médicas sobre os processos de trabaIho do hospital e, por conseguinte, sobre a qualidade dos serviços prestados à população, ratificam uma estrutura organizacional e uma cultura interna em relação ao "cuidado em saúde" e à participação do usuário, que 


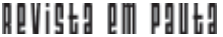

\} INVESTIGANDO A ORGANIZAÇÃO - MIRANDA, A. P. R. S. \}

DOI: 10.12957/rep.2015.21059

sedimenta o isolamento dos saberes e o marginaliza (MERHY, 2007; PINHEIRO, 2008). Tal determinância se dá porque:

O trabalho em saúde é majoritariamente institucionalizado, realizado no espaço ambulatorial ou hospitalar, e resulta de um trabalho coletivo no qual o médico é o elemento central, que detém o controle do processo assistencial e delega atividades a outros profissionais de saúde. (PIRES, 2008, p. 101).

Além das referidas intervenções feitas pelas assistentes sociais, no tocante ao acesso à equipe de saúde e, mais precisamente, à assistência médica, há ainda os casos em que elas precisam intervir para auxiliar os usuários na continuidade do tratamento por meio dos exames solicitados pelos médicos. Esta situação poderá requerer da assistente social duas demandas diferenciadas, apesar de referidas à questão do acesso do usuário: a primeira reporta-se aos exames e procedimentos solicitados pelo médico e que são oferecidos no hospital, mas para os quais não houve prévio agendamento. Desse modo, impõe-se a necessidade de intervenção da assistente social para que tais procedimentos possam ser viabilizados, agilizando o atendimento. Embora seja uma situação contumaz, não há deliberações internas que autentiquem esta prática, tangenciando estas ações para um cariz de improviso da ação do Serviço Social e de sujeição ao usuário.

Já o segundo tipo de demanda diz respeito à orientação para o acesso a exames de alta complexidade, já que, para tanto, o usuário precisará de parecer médico, documentos pessoais e, algumas vezes, também de exames prévios que comprovem a necessidade de exames mais complexos para auxílio no diagnóstico e tratamento. Neste contexto, é comum que o usuário tenha dúvidas sobre como proceder e a quem recorrer, dada a burocracia e a normatização rígidas no sistema de saúde público. Há ainda os casos em que será preciso recorrer ao Ministério Público (MP) ou à realização do exame no setor privado de saúde, caso haja esta possibilidade entre a família.

Ademais, além das demandas decorrentes da consulta médica nomeadas de "necessidades clínicas" -, há cotidianamente a solicitação da intervenção da assistente social para supressão e/ou atendimento do que foi denominado "necessidades sociais" que têm como elemento comum a vulnerabilidade de parcela da população brasileira decorrente do fundamento da sociedade capitalista e que são recorrentes ao Serviço Social, mas apresentadas de forma fragmentada (VASCONCELOS, 2009).

Além da burocracia intrínseca à organização do hospital e extensiva aos serviços da assistência pública de saúde e, portanto, à própria organização da política de saúde, demonstrou-se nos "fluxogramas" (FRANCO; MERHY, 2007) do HULW a dificuldade de acesso do usuário, seja na entrada do serviço, seja na continuidade da assistência pela rede de saúde, atestando a inexistência das "linhas de cuidado" previstas (FRANCO; MAGALHÃES JÚNIOR, 2007). 
Neste momento, e em todos os outros em que os obstáculos se interpõem sobre o usuário no acesso à política de saúde, a figura da assistente social aparece tanto na orientação quanto na interação entre os diversos profissionais no hospital e no sistema de saúde. Firma-se, assim, uma posição de "facilitadora", mas não de "garantidora" do acesso, surtindo efeitos necessários, porém também ratificadores da manutenção da ordem e da organização existentes e reprodutores de uma lógica que não está centrada no usuário, mas na sua colocação como objeto de intervenção, "figura coisificada, receptor", conforme apontado por Franco e Merhy (2007, p. 148).

Pelo "fluxograma" (FRANCO; MERHY, 2007) das clínicas, identificou-se que o objetivo que circunda todos os processos de trabalho nestes ambientes centra-se em garantir que os entraves - pessoais (subjetivos) e familiares, socioeconômicos e culturais, e além dos inerentes à própria organização da rede de assistência à saúde - sejam superados ou minimizados; contudo, também aqui não se observa, em geral, a realização de trabalho multiprofissional, já que as atividades são conectadas apenas quando ocorre a necessidade.

Analisando esses processos de trabalho, atesta-se mais uma vez a posição subsidiária e complementar à prática médica desenvolvida pelo Serviço Social no hospital, a exemplo do que observaram Bezerra e Araújo (2005). Também aqui as demandas chegam ao Serviço Social a partir das necessidades clínicas e sociais observadas. Apesar de ter autonomia relativa nas respostas dadas, não delibera sobre o que fazer, respondendo tanto a demandas suas quanto a demandas burocráticas e repetitivas, que poderiam ser feitas por outros profissionais. Ademais, trabalha pouco a partir de ações que a categoria perceba como necessárias e que componham as atribuições da profissão, tais como a educação e a prevenção em saúde, bem como em pesquisas sociais. Reduz-se, em grande parte, até mesmo a questão do acolhimento e da humanização, às práticas fundadas em valores humanitários que reproduzem ações assistencialistas, apolíticas e/ou conservadoras, em conformidade com o que apontou Vasconcelos (2009) em relação a elas e, ainda, a inexistência de suporte para práticas progressistas no trabalho da categoria na saúde.

Destarte, o Serviço Social vem realizando aquilo que lhe é imposto sem propor mudanças substantivas nas suas ações, embora reaja contra algumas destas determinações e tente empreender transformações, de modo a se adequar ao que prevê o Projeto Ético-Político Profissional. Tais tentativas de romper com o padrão estabelecido decorrem da percepção da perda e/ ou da dificuldade de estabelecer espaços, ocasionada pelos confrontos entre a missão que coloca para si, como categoria - garantir os direitos dos usuários - , e as dificuldades que a realidade da lógica organizacional lhe impõe cotidianamente, além da falta de detenção do poder e dos recursos materiais e políticos da instituição. Restam os recursos cognitivos que, em alguns casos, estão acoplados a práticas conservadoras e funcionalistas. 


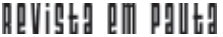

\} INVESTIGANDO A ORGANIZAÇÃO - MIRANDA, A. P. R. S. \}

DOI: 10.12957/rep.2015.21059

Deste modo, lamamoto (1999, p. 24), ao tratar dos efeitos políticoideológicos do seu trabalho, particularizada a esfera do Estado, afirma que, ao atuar com a prestação de serviços sociais, o Serviço Social tem duas possibilidades, quais sejam: "[...] contribuir para o partilhamento do poder e sua democratização, no processo de construção de uma contra-hegemonia no bojo das relações entre as classes". Ou, inversamente ao que propugna o atual Projeto Político, "[...] imprimir outra direção social ao seu trabalho, voltada ao reforço das estruturas e relações de poder preexistentes, os marcos da quotidianeidade".

Em alusão ao que versa lamamoto (1999), no HULW, a primeira possibilidade encontra-se menos patente porque as práticas não estão politicamente organizadas, ao passo em que a segunda torna-se mais evidente, ainda que a intenção seja inversamente proporcional. Isto porque o Serviço Social não conseguiu imprimir para si um projeto de intervenção que se oponha, de fato, aos mecanismos institucionais.

Neste cenário, a lógica do serviço público organizado por uma hierarquia vertical, com observada resistência - arraigada - às mudanças, dificuldade de alocação de recursos financeiros, reduzido controle social, quase inexistência de processos de avaliação e consequente baixo comprometimento, aliados a uma pretensa estabilidade inerente ao serviço público, fazem refluir as iniciativas do Serviço Social. Isto acontece na medida em que as transformações parecem intangíveis, principalmente quando se torna necessário o comprometimento de outras categorias e o respaldo dos que organizam os processos de trabalho a partir dos seus interesses. Dessa forma, falta "[...] potência suficiente para mudar o que está instituído" (FRANCO; MERHY, 2007, p. 157-158), ainda que não sejam ignoradas as mudanças que estabelecem - isoladamente - com os usuários.

\section{Conclusão}

Diante do exposto, infere-se a necessidade, no Serviço Social, da construção de um projeto pautado no planejamento das ações, na utilização adequada dos instrumentos de trabalho disponíveis, na redefinição de papeis junto às equipes e, mais precisamente, na ênfase à reorganização de processos de trabalho tangenciados pelo trabalho multiprofissional (inicialmente a partir dos profissionais com os quais seja mais fácil estabelecer estas mudanças para, a partir daí, espraiar estas alterações).

Tais medidas são imprescindíveis para a configuração do "cuidado em saúde" (MERHY, 2007; PINHEIRO, 2008) e de um trabalho "usuário-centrado" (FRANCO; MAGALHÃES JÚNIOR, 2007), voltado à efetivação do direito e ao respeito às necessidades desse usuário, não como plano ideal, mas em atendimento ao que está previsto em lei desde a sanção da política de saúde como universal e gratuita e do estabelecimento do SUS. 


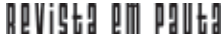

\} INVESTIGANDO A ORGANIZAÇÃO - MIRANDA, A. P. R. S. \}

DOI: $10.12957 /$ rep.2015.21059

O Serviço Social tem trabalhado em prol do direito, mas vem timidamente lançando as bases para tal reorganização. Como não estabeleceu estratégias concretas, nem enquanto categoria nem junto às demais profissões, vem, inadvertida e paradoxalmente, ao que se propõe idealmente, produzindo como um dos seus principais efeitos a manutenção da cultura organizacional vigente e a fragmentação do direito (VASCONCELOS, 2009). Desse modo, na contramão da importância da sua atuação - indiscutível tanto para os usuários, quanto para a instituição -, vem ratificando uma imagem social conservadora que o isola em relação às demais categorias que compõem o trabalho coletivo em saúde.

É certo que o trabalho organizado verticalmente, normativo-burocrático, cerceador de direitos, precarizado e inseguro, respectivamente em decorrência da história da instituição e das mudanças em andamento trazidas com a EBSERH, tem corroborado para a limitação dos produtos do seu trabalho. É dentro desta lógica cerceadora que os principais efeitos estimados oficialmente para o trabalho do assistente social estão localizados.

A despeito do caráter tradicional das solicitações institucionais, o hospital não incorporou o Serviço Social a canais oficiais e regulamentados, nem os estabeleceu na ou pela instituição, seja para favorecer sua cultura normativo-burocrática, seja em prol do direito e do acesso qualificado do usuário (PIRES; MACÊDO, 2006; COSTA, 2006), impelindo, assim, o Serviço Social ao atendimento subordinado às demais categorias, principalmente a médica, o que, em parte, o conduz à manutenção predominante de práticas imediatistas e pouco reflexivas (PIRES, 2008).

Todavia, se o Serviço Social é o espaço reservado ao usuário, à sua vocalização, conforme indicado nos "fluxogramas" (FRANCO; MERHY, 2007), e se seus compromissos estabelecidos na "rede de petição e compromissos" (FRANCO; MERHY, 2007) estão direcionados a esse usuário, é preciso romper com o cariz do favor que paira sobre a imagem social da profissão na instituição. Além disso, resgatar sua autonomia relativa, aliada ao estabelecimento de projetos que se voltem para a participação social, de modo que haja a real apropriação do espaço coletivo. Para tanto, é indispensável que haja estratégias e planos de intervenção, que se faça a compreensão ampliada da rede de assistência à saúde, o desenvolvimento da intersetorialidade e da integralidade, a articulação entre os diferentes saberes. É necessário, também, que o Serviço Social abandone o insulamento, ao passo em que descontrói aspectos tradicionais que ainda perduram sobre a profissão.

O uso das "ferramentas analisadoras" (FRANCO; MERHY, 2007) permitiu o reconhecimento formal do modo como os processos de trabalho se organizam na instituição, viabilizando o engendramento de análises e discussões acerca dos mesmos e desvelando o lugar ocupado pelo usuário no hospital. Contudo, a despeito do que isto representa, correspondeu tão somente ao início de uma trajetória que precisa ser percorrida não apenas 


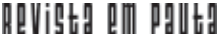

\} INVESTIGANDO A ORGANIZAÇÃO - MIRANDA, A. P. R. S. \}

DOI: $10.12957 /$ rep.2015.21059

pelo Serviço Social, mas pelo conjunto das categorias profissionais que atuam no hospital, cuja particularidade de ser um hospital-escola pode permitir que haja reprodução das ações baseadas em novas posturas, voltadas ao "cuidado em saúde" e "usuário-centradas", caso estas, de fato, venham a ser concretizadas (MEHRY, 2007; PINHEIRO, 2008; FRANCO; MAGALHÃES JÚNIOR, 2007). 


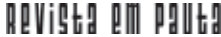

\} INVESTIGANDO A ORGANIZAÇÃO - MIRANDA, A. P. R. S. \}

DOI: $10.12957 /$ rep.2015.21059

\section{Referências}

ABRAHUE. Carta manifesto dos hospitais universitários federais. 2010. Disponível em: <http://www.abrahue.org.br/pdf/carta_manifesto.pdf>. Acesso em: 10 set. 2011.

ACIOLE, G. G. A saúde no Brasil: cartografias do público e do privado. São Paulo: Hucitec; Campinas-SP: Sindicato dos Médicos de Campinas e Região. 2006.

ANDREAZZI, M. de F. S. de. Empresa Brasileira de Serviços Hospitalares: inconsistências à luz da Reforma do Estado. Revista Brasileira de Educação Médica. Rio de Janeiro: Universidade Federal do Rio de Janeiro, v. 37, n. 2, 2013. Disponível em: <http://www.scielo.br/pdf/rbem/v37n2/16.pdf >. Acesso em: 29 jul. 2015.

ANTUNES, R. Adeus ao trabalho? Ensaios sobre as metamorfoses e a centralidade do mundo do trabalho. São Paulo: Cortez. 2003.

AZEVEDO, C. da S. Liderança e processos intersubjetivos em organizações públicas de saúde. Ciência e Saúde Coletiva. São Paulo: Associação Brasileira de Saúde Coletiva (Abrasco), v. 7, n. 2. 2002. Disponível em: <http:// www.scielo.br/pdf/csc/v7n2/10253.pdf>. Acesso em: 29 jul. 2015.

BEHRING, E. R. Brasil em contra-reforma: desestruturação do Estado e perda de direitos. São Paulo: Cortez. 2003.

BEZERRA, S. de O.; ARAÚJO, M. A. D. de. A inserção do assistente social no complexo hospitalar e de atenção à saúde da UFRN no contexto da agudização da questão social. Serviço Social em Revista, Londrina (Paraná), v. 7, n. 2. 2005.

BRASIL. MINISTÉRIO DA SAÚDE. O CNS e a construção do SUS: referências estratégicas para melhora do modelo de atenção à saúde. Brasília: Ministério da Saúde, Conselho Nacional de Saúde. 2003. Disponível em: <http://conselho.saude.gov.br/biblioteca/livros/cnseaconsrucaodosus.pdf>. Acesso em: 29 jul. 2015.

PRESIDÊNCIA DA REPÚBLICA. Lei n. 8.080, de 19 de setembro de 1990 (Lei Orgânica da Saúde). Brasília: Casa Civil. 1990. In: CRESS-SP (org.). Legislação brasileira para o Serviço Social: coletânea de leis, decretos e regulamentos para instrumentação da (o) assistente social. São Paulo: CRESS-SP, 9a. Região. 2007.

. Decreto n. 7.082, de 27 de janeiro de 2010. Brasília: Casa Civil. 2010. Disponível em: <http://www.planalto.gov.br.ccivil_03/_Ato20072010/2010/ Decreto/D7082.htm>. Acesso em: 22 de mar. 2015.

CECILIO, L. C. de O. Modelos tecno-assistenciais em saúde: da pirâmide ao círculo, uma possibilidade a ser explorada. Cad. Saúde Públ. Rio de Ja- 


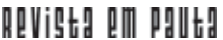

\} INVESTIGANDO A ORGANIZAÇÃO - MIRANDA, A. P. R. S. \}

DOI: 10.12957/rep.2015.21059

neiro: FIOCRUZ, v. 13, n. 3, jul-set. 1997. Disponível em: <http://www. scielo.br/pdf/csp/v13n3/0171.pdf>. Acesso em: 29 jul. 2015.

COSTA, M. D. H. da. O trabalho nos serviços de saúde e a inserção dos(as) assistentes sociais. In: MOTA, A. E. et al. (org.). Serviço Social e saúde. São Paulo: OPAS, OMS, Ministério da Saúde. 2006.

FRANCO, T. B.; MAGALHÃES JÚNIOR, H. M. Integralidade na assistência à saúde: a organização das linhas do cuidado. In: MERHY, E. E. et al. O trabalho em saúde: olhando e experenciando o SUS no cotidiano. São Paulo: Hucitec. 2007.

FRANCO, T. B.; MERHY, E. E. O uso de ferramentas analisadoras para apoio ao planejamento dos serviços de saúde: o caso do Serviço Social do Hospital das Clínicas da Unicamp (Campinas, SP). In: MERHY, E. E. et al. O trabalho em saúde: olhando e experenciando o SUS no cotidiano. São Paulo: Hucitec. 2007.

HADDAD, F.; SILVA, P. B. EMI n. 00383/2010/MP/MEC. Brasília. 2010. Disponível em: <http://www010.dataprev.gov.br/sislex/paginas/45/2010/ 520.htm>. Acesso em: 20 dez. 2014.

IAMAMOTO, M. V. O Serviço Social na contemporaneidade: trabalho e formação profissional. São Paulo: Cortez. 1999.

MATTOS, P. T. L. A formação do Estado regulador. Novos Estudos. Rio de Janeiro: Cebrap, n. 76, nov. 2006.

MENDES, V. L. P. S. Inovação gerencial em serviços públicos de saúde e cidadania. Brasília: Ministério da Saúde. 2002.

MERHY, E. E. Um dos grandes desafios para os gestores do SUS: apostar em novos modos de fabricar os modelos de atenção. In: MERHY, E. E. et al. $O$ trabalho em saúde: olhando e experenciando o SUS no cotidiano. São Paulo: Hucitec. 2007.

MINISTÉRIO DA EDUCAÇÃO. Plano dos povos indígenas. Projeto de revitalização dos hospitais universitários federais. Brasília: Ministério da Educação; Secretaria de Educação Superior. 2010. Disponível em:<https:/ /www.encrypted.google.comsearch?hl=ptBR\&biw=1089\&bih=690\&q=Pro posta+de+Projeto+de+Hospitais+Universitários+e+de+Ensino++Construindo + um+projeto+para+os+HU's.+l\&aq=f\&aqi=\&aql=\&oq=>. Acesso em: 29 jul. 2015.

MIRANDA, A. P. R. de S. Política de saúde no Brasil: conquistas e inflexões. In: CAVALCANTI, P. B.; CARVALHO, R. N.; MIRANDA, A. P. R. de S. (org.) Saúde em foco: visibilidades no contexto atual. João Pessoa: Editora Universitária da UFPB. 2010.

A. P. R. de S. Inserção do Serviço Social nos processos de trabalho em serviços públicos de saúde - concepções e práticas: estudo de caso em 


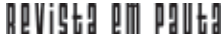

\} INVESTIGANDO A ORGANIZAÇÃO - MIRANDA, A. P. R. S. \}

DOI: $10.12957 /$ rep.2015.21059

um hospital universitário - João Pessoa-PB. Tese (Doutorado) - Programa de Estudos Pós-Graduados em Serviço Social, Pontifícia Universidade Católica, São Paulo. 2011.

MORETTO NETO, L.; SILVA, J. C. da; SCHMITT, V. G. H. Introdução à administração hospitalar. Florianópolis: Departamento de Ciências da Administração - Centro Socioeconômico/UFSC. 2007.

NOGUEIRA, R. P.; SANTANA, J. P. de. Gestão de recursos humanos e reformas do setor público: tendências e pressupostos de uma nova abordagem. 2000. In: WOKSHOP ON GLOBAL HEALTH WORKFORCE STRATEGY, França, dez. 2000.

PEDUZZI, M. Trabalho em equipe. In: PEREIRA, I. B.; LIMA, J. C. F. (org.). Dicionário da educação profissional em saúde. Rio de Janeiro: Fundação Oswaldo Cruz/Escola Politécnica de Saúde Joaquim Venâncio. 2008.

PEDUZZI, M.; SCHRAIBER, L. B. Processo de trabalho em saúde. In: PEREIRA, I. B.; LIMA, J. C. F. (org.). Dicionário da educação profissional em saúde. Rio de Janeiro: Fundação Oswaldo Cruz/Escola Politécnica de Saúde Joaquim Venâncio. 2008.

PEREIRA, P. A. P. Utopias desenvolvimentistas e política social no Brasil. Serviço Social e Sociedade. São Paulo, n. 112, out./dez. 2012.

PINHEIRO, R. Cuidado em saúde. In: PEREIRA, I. B.; LIMA, J. C. F. (org.). Dicionário da educação profissional em saúde. Rio de Janeiro: Fundação Oswaldo Cruz/Escola Politécnica de Saúde Joaquim Venâncio. 2008.

PIRES, D. Reestruturação produtiva e trabalho em saúde no Brasil. São Paulo: Confederação Nacional dos Trabalhadores em Seguridade Social CUT; Annablume. 2008.

PIRES, J. C. de S.; MACÊDO, K. B. Cultura organizacional em organizações públicas no Brasil. RAP. Rio de Janeiro, v. 40, n. 1, jan./fev. 2006.

RABELLO JÚNIOR, W. L. Administração Pública. Rio de Janeiro: Editora Ferreira, s.d. Disponível em: <https://www.editoraferreira.com.br/Medias/ 1/Media/Professores/ToqueDeMestre/WagnerRabello/Toq_05_ Wagner_Rabello.pdf>. Acesso em: 4 dez. 2015.

UNIVERSIDADE FEDERAL DA PARAÍBA. HOSPITAL UNIVERSITÁRIO LAURO WANDERLEY. Plano de reestruturação do hospital universitário Lauro Wanderley. João Pessoa: Universidade Federal da Paraíba. 2010. Dis-ponível em: <http://ebserh.mec.gov.br/images/pdf/contratos_adesao _huf/ufpb/plano_de_reestruturacao_hulw_ufpb.pdf>. Acesso em: 29 jul. 2015.

. Manual operacional do Serviço Social do HULW - revisado. João Pessoa: Divisão de Serviço Social. 2011. mimeo. 


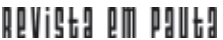

\} INVESTIGANDO A ORGANIZAÇÃO - MIRANDA, A. P. R. S. \}

DOI: 10.12957/rep.2015.21059

VASCONCELOS, A. M. de. A prática do Serviço Social: cotidiano, formação e alternativas na área da saúde. São Paulo: Cortez. 2009.

WEICHERT, M. A. Fundação Estatal no serviço público de saúde: inconsistências e inconstitucionalidades. Revista de Direito Sanitário. São Paulo: USP, v. 10, n. 1, mar/jul. 2009. Disponível em: <http://www.revistas.usp.br/ rdisan/article/view/13148/14954>. Acesso em: 29 jul. 2015.

YASBEK. M. C. O Serviço Social e o movimento histórico da sociedade brasileira. In: CRESS-SP (org.). Legislação brasileira para o Serviço Social: coletânea de leis decretos e regulamentos para instrumentação da(o) assistente social. São Paulo: Cress-SP, 2007.

Recebido em 29 de julho de 2015.

Aprovado para publicação em 08 de novembro de 2015.

DOI: $10.12957 /$ rep.2015.21059

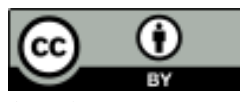

A Revista Em Pauta: Teoria Social e Realidade Contemporânea está licenciada com uma Licença Creative Commons Atribuição 4.0 Internacional. 